УДК [658.7:339.1]:004.8

08.00.13 - Математические и инструментальные методы экономики (экономические науки)

ПРИНЯТИЕ РЕШЕНИЙ ПО НОМЕНКЛАТУРЕ И ОБЪЕМАМ РЕАЛИЗАЦИИ ПРОДУКЦИИ В ТОРГОВОЙ ФИРМЕ С ЦЕЛЬЮ ДОСТИЖЕНИЯ ЗАДАННЫХ ЗНАЧЕНИЙ ПРИБЫЛИ И РЕНТАБЕЛЬНОСТИ ${ }^{1}$

Луценко Евгений Вениаминович

Д.э.Н., К.т.н., профессор

Scopus Author ID: 57188763047

РИНЦ SPIN-код: 9523-7101

prof.lutsenko@gmail.com http://lc.kubagro.ru

Печурина Елена Каримовна

РИНЦ SPIN-код: 1952-4286

geskov@mail.ru

Ткаченко Наталья Андреевна

Магистрант

natalia-mironova1990@mail.ru

Кубанский государственный аграрный

университет им. И.Т. Трубилина,

Россия, 350044, Краснодар, Калинина ул., 13

В предыдущих работах авторов были решены задачи когнитивной структуризации и формализации предметной области, а также синтеза и верификации системно-когнитивных моделей. Данная работа посвящена решению задачи поддержки принятия решений по выбору таких номенклатуры и объемов реализации продукции в торговой фирме, которые обуславливают заданную прибыль и рентабельность

Ключевые слова: АСК-АНАЛИЗ, СИСТЕМА «ЭЙДОС», АВТОМАТИЗИРОВАННЫЙ СИСТЕМНО-КОГНИТИВНЫЙ АНАЛИЗ, УПРАВЛЕНИЕ НОМЕНКЛАТУРОЙ И ОБЪЕМАМИ ЗАКУПОК РЕАЛИЗАЦИИ ТОВАРОВ В ТОРГОВОЙ ФИРМЕ

DOI: http://dx.doi.org/10.21515/1990-4665-154-018
UDC [658.7:339.1]:004.8

08.00.13 - Mathematical and instrumental methods of Economics (economic sciences)

\section{DECISION-MAKING ON NOMENCLATURE AND VOLUMES OF OUTPUT IN A TRADING FIRM WITH THE AIM OF ACHIEVING THE SET REVENUE AND PROFITABILITY}

Lutsenko Evgeniy Veniaminovich

Dr.Sci.Econ., Cand.Tech.Sci., professor

Scopus Author ID: 57188763047

RSCI SPIN-code: 9523-7101

prof.lutsenko@gmail.com http://lc.kubagro.ru

Pechurina Elena Karimovna

RSCI SPIN-code: 1952-4286

geskov@mail.ru

Tkachenko Natalia Andreevna master's degree student natalia-mironova1990@mail.ru

Kuban State Agrarian University named after I.T. Trubilin, Russia,

350044, Krasnodar, Kalinina str., 13

In their previous works, the authors solved the problem of cognitive structuring and formalization of the subject area, as well as the synthesis and verification of system-cognitive models. This work is devoted to the problem of forecasting the impact of the nomenclature and sales volumes on the profit and profitability of a trading company

Keywords: ASC-ANALYSIS, "EIDOS" SYSTEM, AUTOMATED SYSTEM-COGNITIVE ANALYSIS, MANAGEMENT OF THE NOMENCLATURE AND VOLUME OF PURCHASES OF SALES OF GOODS IN A TRADING COMPANY

В работе [1] решена задача-1 когнитивной структуризации и формализации предметной области, а в работе [2] - задача-2 синтеза и верификации системно-когнитивных моделей (СК-модели).

\footnotetext{
${ }^{1}$ Работа выполнена при финансовой поддержке РФФИ, проект № 17-02-00064-ОГН.
} 
На основе созданных СК-моделей могут быть решены последующие задачи:

3) прогнозирования;

4) поддержки принятия решений;

5) исследования объекта моделирования.

Решению 4-й из этих задач и посвящена данная статья. Решением задачи поддержки принятия решений является SWOT-анализ. Однако проведение самого SWOT-анализа часто является проблемой, т.к. в нем используются слабо формализованные экспертные оценки. Эта проблема решена путем разработки автоматизированного SWOT-анализа, который основан на автоматизированном системно-когнитивном моделировании. На рисунках 1 и 2 приведены формы автоматизированного SWOT-анализа, отражающие систему детерминации целевых (т.е. максимальных) значений прибыли и рентабельности фирмы.

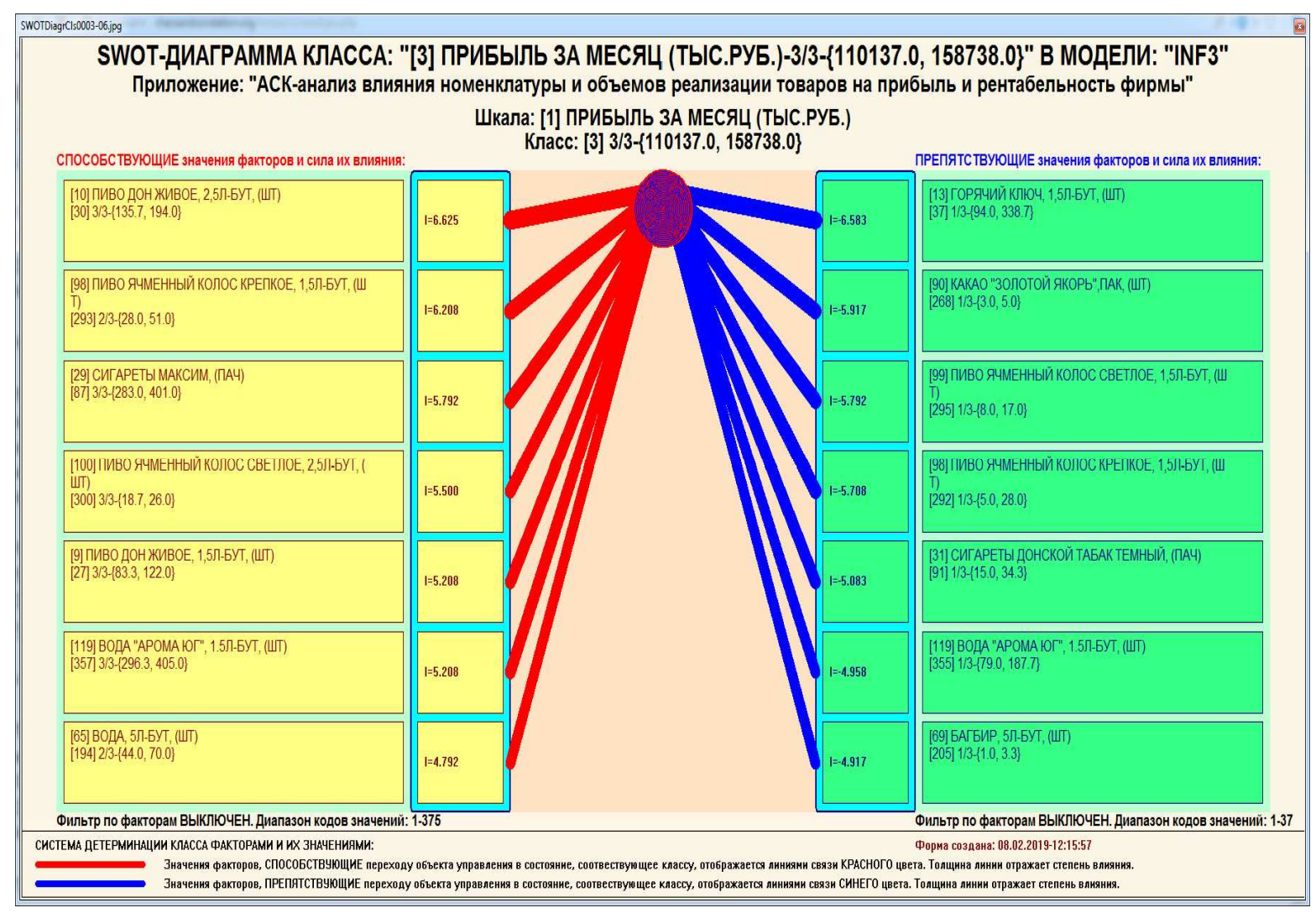

Рисунок 1. Система детерминации состояния фирмы: Код=3, ПРИБЫЛЬ ЗА МЕСЯЦ (ТЫС.РУБ.)-3/3-\{110137.0000000, 158738.0000000\} 


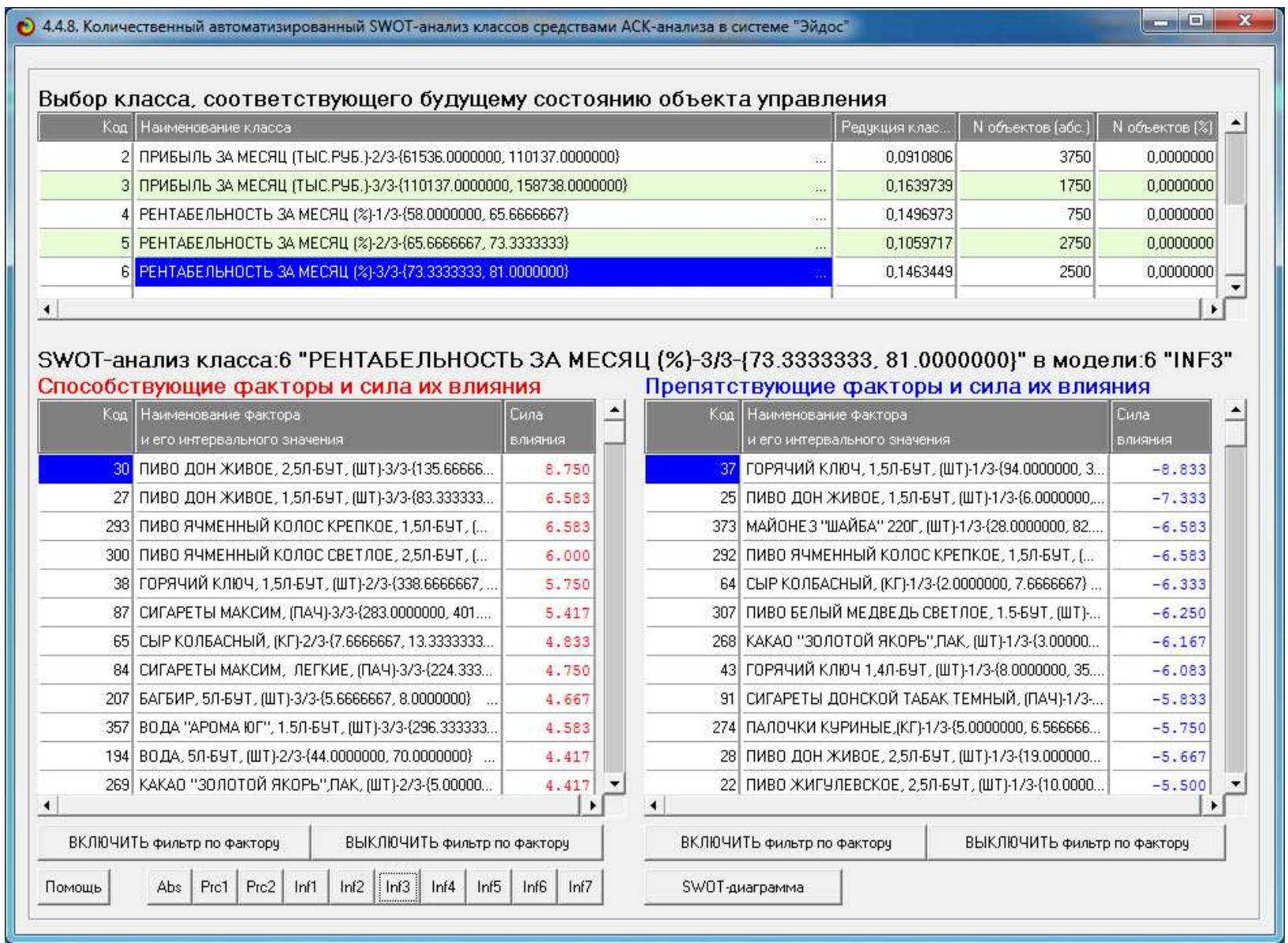

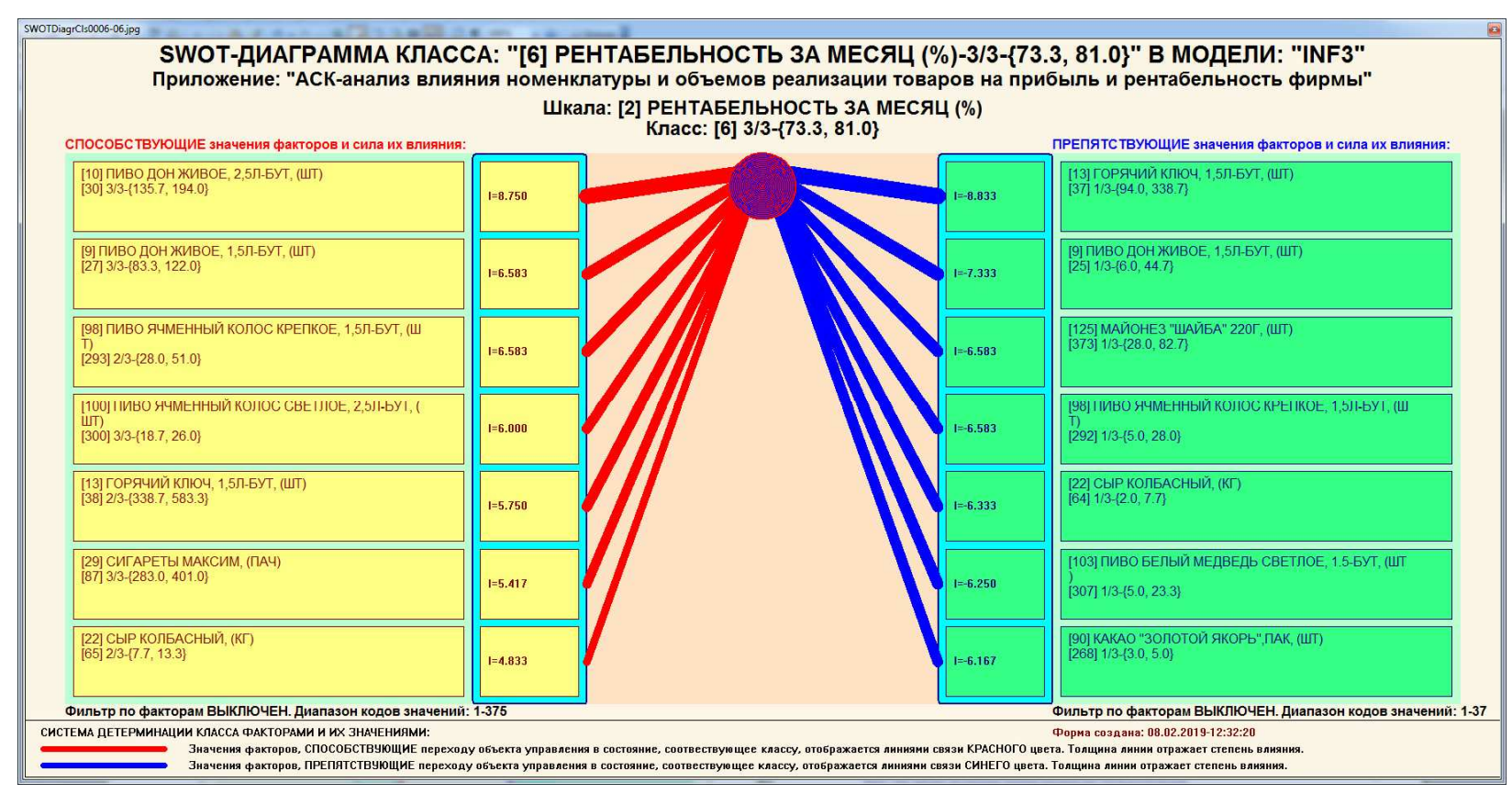

Рисунок 2. Система детерминации состояния фирмы: Код=6,

РЕНТАБЕЛЬНОСТЬ ЗА МЕСЯЦ (\%)-3/3-\{73.3333333, 81.0000000\}

Ниже рассмотрим алгоритм принятия решений, использующий как результаты как SWOT-анализа классов, так и результаты прогнозирования 
и кластерного анализа классов и значений факторов. Идея, которая лежит в основе этого алгоритма состоит в том, чтобы заменить некоторое значение фактора, которое рекомендуется SWOT-анализом но по каким-либо причинам не может быть использовано, на другое, сходное с ним по влиянию на объект моделирования, по результатам кластерного анализа значений факторов. На этой идее и основан алгоритм принятия управляющих решений в АСК-анализе и системе «Эйдос», приведенный ниже.

Обратим внимание на то, что приведенный на рисунке 3 алгоритм принятия решений используется непосредственно в цикле управления и предусматривает постоянную адаптацию модели, а случае необходимости и еe пересинтез, что обеспечивает учет динамики моделируемой предметной области, т.е. как самого объекта управления, так и окружающей среды.

Таким образом на основе изложенного можно сделать обоснованный вывод о том, что поставленная в рабате задача поддержки принятия решений по выбору таких номенклатуры и объемов реализации продукции в торговой фирме, которые обуславливают заданную прибыль и рентабельность, успешно решена.

Из сравнения SWOT-диаграмм на рисунках 1 и 2 видно, что для достижения высокой прибыли и рентабельности необходимы сходные значения обуславливающих факторов, в качестве которых выступают номенклатуры и объемы реализации товаров. Из этого можно сделать вывод о возможности достижения обоих этих состояний моделируемого объекта одновременно, т.е. они не являются альтернативными и постановка цели об их одновременном достижении является вполне корректной. 


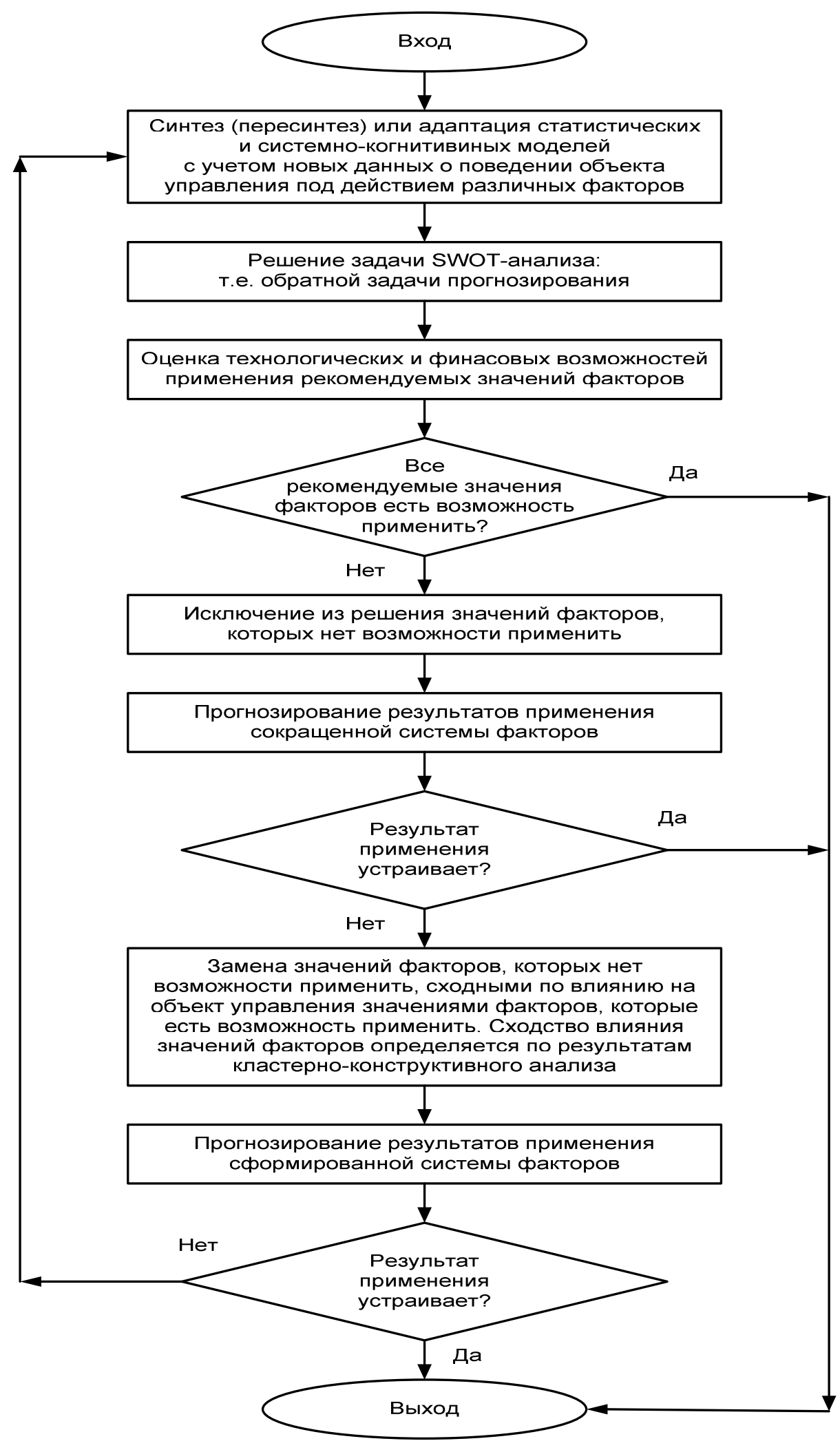

Рисунок 3. Алгоритм принятия управляющих решений в АСК-анализе и системе «Эйдос»

Более подробное описание приведенного алгоритма принятия решений приведено в работе [9]. 


\section{Лumepamypa:}

1. Луценко Е.В., Барановская Т.П. Системно-когнитивный анализ в управлении номенклатурой и объемами закупки-реализации продукции в торговой агрофирме: когнитивная структуризация и формализация предметной области // НОВЫЕ ТЕХНОЛОГИИ. Вып. 3, 2018 г. - Майкоп: изд-во ФГБОУ ВО «МГТУ», 2018. - 135 139. http://lib.mkgtu.ru/images/stories/journal-nt/2018-03/019.pdf

2. Луценко Е.В., Барановская Т.П. Системно-когнитивный анализ в управлении номенклатурой и объемами закупки-реализации продукции в торговой агрофирме: формальная постановка задачи и синтез модели // В сборнике: Актуальные аспекты реализации стратегии модернизации России: поиск модели эффективного хозяйственного развития. Сборник статей XXXIII Международной научнопрактической конференции. Под редакцией Г.Б. Клейнера, В.В. Сорокожердьева, 3.М. Хашевой. 2018. С. 146-151. https://elibrary.ru/item.asp?id=36420746

3. Орлов А.И., Луценко Е.В. Системная нечеткая интервальная математика. Монография (научное издание). - Краснодар, КубГАУ. 2014. - 600 с. ISBN 978-594672-757-0. http://elibrary.ru/item.asp?id=21358220

4. Луценко Е.В. Метризация измерительных шкал различных типов и совместная сопоставимая количественная обработка разнородных факторов в системнокогнитивном анализе и системе «Эйдос» / Е.В. Луценко // Политематический сетевой электронный научный журнал Кубанского государственного аграрного университета (Научный журнал КубГАУ) [Электронный ресурс]. - Краснодар: КубГАУ, 2013. №08(092). C. 859 - 883. - IDA [article ID]: 0921308058. - Режим доступа: http://ej.kubagro.ru/2013/08/pdf/58.pdf, 1,562 у.п.л.

5. Луценко Е.В. Метод когнитивной кластеризации или кластеризация на основе знаний (кластеризация в системно-когнитивном анализе и интеллектуальной системе «Эйдос») / Е.В. Луценко, В.Е. Коржаков // Политематический сетевой электронный научный журнал Кубанского государственного аграрного университета (Научный журнал КубГАУ) [Электронный ресурс]. - Краснодар: КубГАУ, 2011. - №07(071). С. 528 - 576. - Шифр Информрегистра: 042110001210253, IDA [article ID]: 0711107040. Режим доступа: http://ej.kubagro.ru/2011/07/pdf/40.pdf, 3,062 у.п.л.

6. Луценко Е.В. Количественный автоматизированный SWOT- и PEST-анализ средствами АСК-анализа и интеллектуальной системы «Эйдос-Х++» / Е.В. Луценко // Политематический сетевой электронный научный журнал Кубанского государственного аграрного университета (Научный журнал КубГАУ) [Электронный peсурс]. - Краснодар: КубГАУ, 2014. - №07(101). С. 1367 - 1409. - IDA [article ID]: 1011407090. - Режим доступа: http://ej.kubagro.ru/2014/07/pdf/90.pdf, 2,688 у.П.л.

7. Луценко Е.В. Системно-когнитивное моделирование влияния агротехнологий на урожайность и качество пшеницы и решение задач прогнозирования, поддержки принятия решений и исследования предметной области / Е.В. Луценко, Е.К. Печурина // Политематический сетевой электронный научный журнал Кубанского государственного аграрного университета (Научный журнал КубГАУ) [Электронный peсурс]. - Краснодар: КубГАУ, 2019. - №03(147). С. 62 - 128. - IDA [article ID]: 1471903015. - Режим доступа: http://ej.kubagro.ru/2019/03/pdf/15.pdf, 4,188 у.п.л.

8. Луценко, Е.В. Инвариантное относительно объемов данных нечеткое мультиклассовое обобщение F-меры достоверности моделей Ван Ризбергена в АCКанализе и системе «Эйдос» / Е.В. Луценко // Политематический сетевой электронный научный журнал Кубанского государственного аграрного университета (Научный журнал КубГАУ) [Электронный ресурс]. - Краснодар: КубГАУ, 2017. - №02(126). С. 1 - 32. - IDA [article ID]: 1261702001. - Режим доступа: http://ej.kubagro.ru/2017/02/pdf/01.pdf, 2 у.П.л. 
9. Луценко Е.В. Автоматизация Функционально-стоимостного анализа и метода "Директ-костинг" на основе АСК-анализа и системы "Эйдос" (автоматизация управления натуральной и финансовой эффективностью затрат без содержательных технологических и финансово-экономических расчетов на основе информационных и когнитивных технологий и теории управления) / Е.В. Луценко // Политематический сетевой электронный научный журнал Кубанского государственного аграрного университета (Научный журнал КубГАУ) [Электронный ресурс]. - Краснодар: КубГАУ, 2017. - №07(131). С. 1 - 18. - IDA [article ID]: 1311707001. - Режим доступа: http://ej.kubagro.ru/2017/07/pdf/01.pdf, 1,125 у.П.л.

10. Луценко, Е.В. Открытая масштабируемая интерактивная интеллектуальная online среда для обучения и научных исследований на базе АСК-анализа и системы «Эйдос» / Е.В. Луценко // Политематический сетевой электронный научный журнал Кубанского государственного аграрного университета (Научный журнал КубГАУ) [Электронный ресурс]. - Краснодар: КубГАУ, 2017. - №66(130). С. 1 - 55. - IDA [article ID]: 1301706001. - Режим доступа: http://ej.kubagro.ru/2017/06/pdf/01.pdf, 3,438 у.п.л. (http://lc.kubagro.ru/aidos/Presentation_Aidos-online.pdf)

11. Луценко Е.В., Открытая масштабируемая интерактивная интеллектуальная online среда «Эйдос» («Эйдоc-online»). Свид. РосПатента РФ на программу для ЭВМ, Заявка № 2017618053 от 07.08.2017, Гос.рег.№ 2017661153, зарегистр. 04.10.2017. Режим доступа: http://lc.kubagro.ru/aidos/2017661153.jpg, 2 у.п.л.

12. Луценко Е.В. Проблемы и перспективы теории и методологии научного познания и автоматизированный системно-когнитивный анализ как автоматизированный метод научного познания, обеспечивающий содержательное феноменологическое моделирование / Е.В. Луценко // Политематический сетевой электронный научный журнал Кубанского государственного аграрного университета (Научный журнал КубГАУ) [Электронный ресурс]. - Краснодар: КубГАУ, 2017. №03(127). С. 1 - 60. - IDA [article ID]: 1271703001. - Режим доступа: http://ej.kubagro.ru/2017/03/pdf/01.pdf, 3,75 у.п.л.

\section{References}

1. Lucenko E.V., Baranovskaya T.P. Sistemno-kognitivny`j analiz v upravlenii nomenklaturoj i ob"emami zakupki-realizacii produkcii v torgovoj agrofirme: kognitivnaya strukturizaciya i formalizaciya predmetnoj oblasti // NOVY`E TEXNOLOGII. Vy`p. 3, 2018 g. - Majkop: izd-vo FGBOU VO «MGTU», $2018 . \quad$ - 135 -139. http://lib.mkgtu.ru/images/stories/journal-nt/2018-03/019.pdf

2. Lucenko E.V., Baranovskaya T.P. Sistemno-kognitivny`j analiz v upravlenii nomenklaturoj i ob"emami zakupki-realizacii produkcii v torgovoj agrofirme: formal naya postanovka zadachi i sintez modeli // V sbornike: Aktual`ny`e aspekty` realizacii strategii modernizacii Rossii: poisk modeli e`ffektivnogo xozyajstvennogo razvitiya. Sbornik statej XXXIII Mezhdunarodnoj nauchno-prakticheskoj konferencii. Pod redakciej G.B. Klejnera, V.V. Sorokozherd eva, Z.M. Xashevoj. 2018. S. 146-151. https://elibrary.ru/item.asp?id=36420746

10. Orlov A.I., Lucenko E.V. Sistemnaya nechetkaya interval naya matematika. Monografiya (nauchnoe izdanie). - Krasnodar, KubGAU. 2014. - 600 s. ISBN 978-5-94672757-0. http://elibrary.ru/item.asp?id=21358220

11. Lucenko E.V. Metrizaciya izmeritel’ny`x shkal razlichny`x tipov i sovmestnaya sopostavimaya kolichestvennaya obrabotka raznorodny`x faktorov $\mathrm{v}$ sistemno-kognitivnom analize i sisteme «E`jdos» / E.V. Lucenko // Politematicheskij setevoj e`lektronny j nauchny`j zhurnal Kubanskogo gosudarstvennogo agrarnogo universiteta (Nauchny j zhurnal KubGAU) [E’lektronny`j resurs]. - Krasnodar: KubGAU, 2013. - №08(092). S. 859 - 883. - IDA 
[article ID]: 0921308058. - Rezhim dostupa: http://ej.kubagro.ru/2013/08/pdf/58.pdf, 1,562 u.p.l.

12. Lucenko E.V. Metod kognitivnoj klasterizacii ili klasterizaciya na osnove znanij (klasterizaciya $\mathrm{v}$ sistemno-kognitivnom analize i intellektual`noj sisteme «E`jdos») / E.V. Lucenko, V.E. Korzhakov // Politematicheskij setevoj e`lektronny`j nauchny`j zhurnal Kubanskogo gosudarstvennogo agrarnogo universiteta (Nauchny`j zhurnal KubGAU) [E`lektronny`j resurs]. - Krasnodar: KubGAU, 2011. - №07(071). S. 528 - 576. - Shifr Informregistra: 042110001210253, IDA [article ID]: 0711107040. - Rezhim dostupa: http://ej.kubagro.ru/2011/07/pdf/40.pdf, 3,062 u.p.1.

13. Lucenko E.V. Kolichestvenny`j avtomatizirovanny`j SWOT- i PEST-analiz sredstvami ASK-analiza i intellektual'noj sistemy` «E`jdos-X++» / E.V. Lucenko // Politematicheskij setevoj e`lektronny`j nauchny’j zhurnal Kubanskogo gosudarstvennogo agrarnogo universiteta (Nauchny’j zhurnal KubGAU) [E`lektronny`j resurs]. - Krasnodar: KubGAU, 2014. - №07(101). S. 1367 - 1409. - IDA [article ID]: 1011407090. - Rezhim dostupa: http://ej.kubagro.ru/2014/07/pdf/90.pdf, 2,688 u.p.1.

14. Lucenko E.V. Sistemno-kognitivnoe modelirovanie vliyaniya agrotexnologij na urozhajnost` i kachestvo pshenicy i reshenie zadach prognozirovaniya, podderzhki prinyatiya reshenij i issledovaniya predmetnoj oblasti / E.V. Lucenko, E.K. Pechurina // Politematicheskij setevoj e’lektronny`j nauchny’j zhurnal Kubanskogo gosudarstvennogo agrarnogo universiteta (Nauchny’j zhurnal KubGAU) [E`lektronny`j resurs]. - Krasnodar: KubGAU, 2019. - №03(147). S. 62 - 128. - IDA [article ID]: 1471903015. - Rezhim dostupa: http://ej.kubagro.ru/2019/03/pdf/15.pdf, 4,188 u.p.1.

15. Lucenko, E.V. Invariantnoe otnositel`no ob“emov danny`x nechetkoe mul tiklassovoe obobshhenie F-mery` dostovernosti modelej Van Rizbergena v ASK-analize i sisteme «E`jdos» / E.V. Lucenko // Politematicheskij setevoj e`lektronny`j nauchny`j zhurnal Kubanskogo gosudarstvennogo agrarnogo universiteta (Nauchny j zhurnal KubGAU) [E`lektronny`j resurs]. - Krasnodar: KubGAU, 2017. - №02(126). S. 1 - 32. - IDA [article ID]: 1261702001. - Rezhim dostupa: http://ej.kubagro.ru/2017/02/pdf/01.pdf, 2 u.p.l.

16. Lucenko E.V. Avtomatizaciya Funkcional no-stoimostnogo analiza i metoda "Direkt-kosting" na osnove ASK-analiza i sistemy` "E’jdos" (avtomatizaciya upravleniya natural`noj i finansovoj e`ffektivnost`yu zatrat bez soderzhatel`ny`x texnologicheskix i finansovo-e`konomicheskix raschetov na osnove informacionny`x i kognitivny`x texnologij i teorii upravleniya) / E.V. Lucenko // Politematicheskij setevoj e`lektronny`j nauchny`j zhurnal Kubanskogo gosudarstvennogo agrarnogo universiteta (Nauchny j zhurnal KubGAU) [E`lektronny`j resurs]. - Krasnodar: KubGAU, 2017. - №07(131). S. 1 - 18. - IDA [article ID]: 1311707001. - Rezhim dostupa: http://ej.kubagro.ru/2017/07/pdf/01.pdf, 1,125 u.p.l.

17. Lucenko, E.V. Otkry`taya masshtabiruemaya interaktivnaya intellektual`naya online sreda dlya obucheniya i nauchny`x issledovanij na baze ASK-analiza i sistemy` «E`jdos» / E.V. Lucenko // Politematicheskij setevoj e`lektronny`j nauchny`j zhurnal Kubanskogo gosudarstvennogo agrarnogo universiteta (Nauchny`j zhurnal KubGAU) [E`lektronny`j resurs]. - Krasnodar: KubGAU, 2017. - №66(130). S. 1 - 55. - IDA [article ID]: 1301706001. - Rezhim dostupa: http://ej.kubagro.ru/2017/06/pdf/01.pdf, 3,438 u.p.l. (http://lc.kubagro.ru/aidos/Presentation_Aidos-online.pdf)

18. Lucenko E.V., Otkry taya masshtabiruemaya interaktivnaya intellektual naya online sreda «E`jdos» («E jdos-online»). Svid. RosPatenta RF na programmu dlya E`VM, Zayavka № 2017618053 ot 07.08.2017, Gos.reg.№ 2017661153, zaregistr. 04.10.2017. Rezhim dostupa: http://lc.kubagro.ru/aidos/2017661153.jpg, 2 u.p.l.

3. Lucenko E.V. Problemy` i perspektivy` teorii i metodologii nauchnogo poznaniya i avtomatizirovanny j sistemno-kognitivny`j analiz kak avtomatizirovanny j metod nauchnogo poznaniya, obespechivayushhij soderzhatel noe fenomenologicheskoe modelirovanie / E.V. 
Lucenko // Politematicheskij setevoj e`lektronny`j nauchny j zhurnal Kubanskogo gosudarstvennogo agrarnogo universiteta (Nauchny`j zhurnal KubGAU) [E`lektronny`j resurs]. - Krasnodar: KubGAU, 2017. - №03(127). S. 1 - 60. - IDA [article ID]: 1271703001. - Rezhim dostupa: http://ej.kubagro.ru/2017/03/pdf/01.pdf, 3,75 u.p.l. 